\title{
EL FRACASO ESCOLAR Y LAS FUNCIONES ESTRUCTURALES DE LA ESCUELA: UNA PERSPECTIVA CRÍTICA.
}

\author{
DR. Jesús M. ReDONDO
}

Cuando en 1988 se publicó desde el Servicio de Educación Compensatoria un informe de divulgación para el País Vasco sobre los programas de Transición Europeos, señalábamos al final Le la reflexión sobre la situación de los jóvenes del País Vasco, que uno de los ámbitos de actuación :H.gente y preferente era 'la reducción del fracaso y del abandono escolar'.

'Dentro de este ámbito hay' que hacer una adecuada distinción de niveles:

a) Un plano del fracaso escolar es lo que podemos denominar como 'fracaso acadénico: I.' 'fracaso académico' se da en aquellos jóvenes que no llegan al 'nivel exigido'. Este concepto thivel puede tener; al mismo tiempo, diversas acepciones:

- Nivel que pide el programa oficial para la certificación.

- Nivel medio de la población, exigido para considerar que no hay un fracaso.

- Nivel al que puede aspirar un sujeto determinado.

b) El fracaso del sistema (real o aparente) en cifras macro-sociales.

c) El fracaso personal de los sujetos que en su proceso de socialización (primer objetivo it la escuela democrática) interiorizan un autoconcepto muly' negativo.

d) El fracaso de determinados colectivos que por condiciones socioeconómicas y de "arginalidad, no puede acceder al 'nivel' para los procesos normalizados de la escuela.

Es evidente que cada uno de los planos tiene un tratamiento propio y una propuesta de Juciones especifica' (Gobiemo Vasco, 1988).

Al abordar aquí el fracaso escolar queremos detenernos a analizar cada uno de los niveles planos del mismo. Doise (1978; Perret-Clermont, 1979, 5), plantea también cuatro niveles de inálisis:

a.- El estudio psicológico enfocado sobre el individuo.

b.- Las relaciones interindividuales dentro de la escuela.

c.- Las relaciones intergrupos dentro de la escuela.

d.- El medio o contexto social de la escuela.

Spartamento Psicología. Universidad de Chile. jredondo@abello dic uchilecl 
En otros lugares hemos abordado los mecanismos internos a la escuela que contribuyen al fracaso de determinados colectivos e individuos $(b-c)^{\prime}$ y hemos señalado algunos elementos de la vivencia del fracaso en los propios jóvenes (a)². Pero aquí nos limitaremos a abordar las funciones del subsistema educativo en el contexto de la sociedad occidental actual (d). Es evidente que el llamado 'fracaso académico' es la señal que expresa u oculta estos tres niveles de fracaso.

\section{LA CRISIS MUNDIAL DE LA EDUCACIÓN}

La escuela en la sociedad capitalista democrática se ha convertido en escuela de masas porque durante la etapa de crecimiento económico (1948-1968) ha resultado funcional tanto a la acumulación capitalista fruto de la expansión económica keynesiana, como a la legitimación social de la democracia a través de la llamada 'igualdad de oportunidades'.

En la coyuntura actual la escuela sigue siendo escuela de masas y se amplía su cobertura (prolongación de la escolaridad obligatoria, masiva afluencia a la escuela post-obligatoria...), pero a nadie se le escapa la percepción de que se hace no tanto por su 'utilidad' al actual proceso de acumulación internacional de capital, cuanto por la necesidad de mantener la legitimidad. Así se la utiliza como alternativa a la cesantía, aún cuando ya es evidente que no garantiza la igualdad de oportunidades, sino que, en la mayoría de los casos, reproduce las desigualdades de origen. De esta forma es más una institución de control social de los jóvenes reducidos a consumidores pasivos, sumisos y disciplinados, que oportunidad para 'aprender a ser' (Faure, 1972).

Pero analicemos con algún detenimiento distintos aspectos y ángulos del problema planteado. La escuela trata de cumplir dentro del sistema social tres grandes funciones (Page, $1977,24)$ que responden a los requerimientos de los tres subsistemas centrales en los que podemos articular la realidad social: el tecno-económico, el socio-político y el cultural-ideológico Para el tecno-económico la finalidad de la escuela es adaptar la formación, permanentemente, a las necesidades de la economía y a su lógica de acumulación. Para el socio-político la finalidad es integrar en el orden social democrático, legitimándolo. Para el cultural-ideológico se trata de motivar para aprender y salvaguardar la herencia cultural, fundamentalmente articulada en 'valores'.

Es adecuado esperar que cuando el equilibrio inestable y conflictivo entre los tres subsistemas se resquebraja de forma manifiesta e incontrolable como ocurre en las últimas décadas ${ }^{3}$, la escuela entra en crisis, y es objeto de 'críticas' desde todos los ámbitos y en todas sus funciones.

Ya a finales de los 60 empezaba a constatarse que se daba un desajuste entre lo esperado y lo conseguido con la masificación escolar. Así. Combs $(1968,239-243)$ al recapitular los factores causantes de la 'crisis mundial de la educación' señalaba los siguientes:

- El aumento de los alumnos por la presión demográfica que desborda las previsiones.

- La escasez de recursos destinados a la educación y el aumento constante de los costos de la misma por alumno.

- La inadaptación de los resultados, tanto para el mercado como para los individuos.

- La ineficacia e ineficiencia de los métodos y la organización escolar.

McLuhan en su 'aldea global' (1968) ponía su acento particular al señalar que la escuela no era el único canal de educación, y que incluso la mayor parte de los aprendizajes significativos para la persona se dan fuera de ella, a través de los llamados 'medios de comunicación de masas'. No es extraño que el mismo Combs postule, además de la innovación y la financiación del sistema

I J. M. Reifondo. (1997). 'La dinámica escolar. de la diferencia a la desigualdad'. Revista de Psicología de la Universidad de Chile. Vol. VI. 1997. Págs. 7-18

2) M. Redondo y uros. (1998) 'El mundo de los jóvenes y la reforma de la enseñanza mediá. Revista de Psicología de la Universidad de Chile. Vol VI 1998. Págs $35-49$

3 J. M Redondo (1995) Análisis de la situación psicosocial de los jovenes desfin orecidos y propuesta de un programa integral de garantia social Tesis Dectorit. Lniversidad de Deusto. Edición Microficha. Bithao 1995 Págs. 9-50. 
escolar, el desarrollo de la formación informal (Combs, 1966, 243-259).

Faure, a instancias de la UNESCO, elabora el informe 'Aprender a Ser', y tras señalar las agudas problemáticas afirma que su único camino de evolución es sustraerse a los criterios de las instancias económicas, políticas e incluso culturales y optar por una 'educación permanente' en el marco de una 'ciudad educativa', cuyo objeto sea 'permitir al hombre ser el mismo' (Faure, 1972, 3842).

Es precisamente el permitir al hombre serlo y criticar la manipulación del conocimiento por la escuela como institución al servicio del orden (desorden) establecido, lo que lleva al grupo reunido en tomo al CIDOC ${ }^{\dagger}$ a propugnar la 'desescolarización'. Goodman (1970), Illich (1970) y Reimer (1970) son los autores más conocidos de esta corriente crítica cuyos postulados centrales señalan la incapacidad de la escuela para promover la auténtica educación; ya que la escuela upone un despilfarro de recursos, fomenta la desigualdad y enseña fundamentalmente a depender, consumir, competir y vivir como clientela de una sociedad 'escolarizada' (burocratizada). Su alternativa pretende desburocratizar y liberar la educación del sistema escolar.

Desde una perspectiva marxista, especialmente estructuralista siguiendo a Althusser (1970); Baudelot y Establet (1976), Bourdieu - Passeron (1970). Bowles y Gintis (1976), Lerena (1976, 1983) y Fernández Enguita (1985, 1987. 1990). analizan las funciones que cumple la escuela en sus prácticas reales más que en sus discursos ideológicos de justificación. De esta forma destacan sus funciones reproductoras y funcionales a los requerimientos del subsistema económico en la sociedad capitalista. Ya que la ideología surge como expresión u ocultación de la realidad; y puesto que ésta es sobre todo relaciones sociales, las instituciones que crean y difunden la ideología deben ser analizadas como relaciones sociales. La escuela, como institución de reproducción ideológica, debe ser analizada más en su 'cómo enseña' que en su 'qué enseña'; ya que aquél es su contenido real y éste su ocultamiento.

Todas estas críticas suponen el descubrir de forma descarnada los límites funcionalesdisfuncionales de las escuelas para el sistema social y su articulación.

\section{LA FUNCIONALIDAD ECONÓMICA DE LA ESCUELA.}

\section{‥ Educación y trabajo: escuela y empleo.}

Que la escuela es de hecho prioritariamente funcional al subsistema económico-tecnológico, o debería ser motivo de desgarramiento hipócrita de las conciencias, sino asunción de las prioridades materiales en la construcción objetiva de la realidad humana. Lo problemático es su inilateralidad, así como la legitimidad política y ética del modelo económico y tecnológico actual.

Como bien analiza Fernández Enguita en su libro 'La cara oculta de la escuela'; la escuela a a finales del siglo XVIII asume la necesidad de preparar, no tanto en el terreno cognitivo y de contenidos sino sobre todo en el de 'actitudes' y 'hábitos', a las clases populares para los requerimientos de la incipiente industrialización.

El instrumento idóneo era la escuela. No es que las escuelas se crearan necesariamente con este propósito, ni que ya no pudieran o fueran a dejar de cumplir otras funciones: sencillamente estaban ahi y podia sacarse buen partido de ellas. En 1772. William Powell ya habia visto la educación como medio de adquirir o instalar el 'hábito de la laboriosidad', y el reverendo William Turner, en 1786, alababa las escuelas dominicales de Raikes como 'un espectáculo de orden y regularidad' y citaba a un fabricante de Gloucester afimando que los niños que asistian a las escuelas 
se volvian 'más tratables y obedientes y menos pendencieros y vengativos'.

'El acento se desplazó entonces de la educación religiosa y, en general, del adoctrinamiento ideológico a la disciplina material, a la organización de la experiencia escolar de modo que generara en los jóvenes los hábitos, las formas de comportamiento, las disposiciones y los rasgos de carácter más adecuados para la industria'. (Fernández Enguita, 1990, 127).

Es por ello que recomienda una revisión de la historia de la pedagogía y de la escuela para, sin dejarse llevar por las formulaciones ideológicas articuladas en los discursos, analizar las prácticas y constatar la auténtica función social de la escuela en su proceso histórico occidental.

Esperamos que a la altura de la reflexión se perciba que, como se explicita en el título que encabeza este apartado, se ha ido produciendo una reducción (a modo de bonsai) del concepto de educación al de escuela, y del de trabajo a empleo.

No es que la función prioritaria de la educación sea ser funcional al subsistema tecnoeconómico; sino que por efecto de la reducción, operada por la modernidad: de lo real a lo racional, de lo racional a lo eficiente, y de lo eficiente al máximo rendimiento; la educación se reduce a escuela, la escuela a normas (normalización), y las normas a pura disciplina (Foucault, 1976). Esta reducción es paralela a la operada en el proceso industrial, en el que el trabajo se reduce a empleo alienado en aras del máximo rendimiento para el capital y su lógica de acumulación.

Esta disciplina de los cuerpos que se extiende a todas las instituciones de masas burocratizadas que configuran los cuerpos sociales (Corporaciones, Administraciones...) pretende constituirse en 'tecnología del cuerpo cuya finalidad es el control de la interioridad y la instauración de un poder' (Chamboredon, 1983, 87) desde fuera, pero asumido desde dentro. El intento no es tanto el favorecer el autocontrol o autodominio personal en función de unos valores asumidos libremente sino 'la reproducción de la fuerza de trabajo popular por medio de prácticas que si bien afectan al deseo, al cuerpo, a la sexualidad o al espíritu, lo hacen en primer lugar y siempre sobre el fondo de la lucha de clases' (Charlot - Figeat; Fernández Enguita, 1990, 159), es decir, sobre el fondo de las relaciones sociales.

Es claro, por otra parte, que no podía ser de otra manera; pues como señala Vygotsky, la vida mental hay que situarla en el agregado de las relaciones sociales internalizadas. Consiste en 'internalizar el conocimiento externo y convertirlo en herramienta para el control consciente' (Wertsch. 1988). El acto social es precondición de la conciencia individual. Pero no sólo el acto inmediato, sino el acto como expresión de formas configuradas históricamente de control de la actividad (Bruner, 1981, 8). Esa configuración histórica opera sobre todo a través del lenguaje, pero también de ese otro lenguaje que constituyen los ritos, las reglas y las normas de las instituciones sociales.

De forma que Joel Sprig, refiriéndose en particular a la expansión y generalización de la escuela secundaria, es más categórico:

'el propósito de esta organización es producir lo que Wilhelm Reich ha llamado la 'coraza caracterial', una serie de rasgos caracteriales tipificados por amor hacia, y deseo de autoridad, orden, seguridad, sumisión y burocracia; yu sentido compulsivo del deber' (Fernández Enguita, 1990, 161).

Es por la escuela, en sus prácticas disciplinadas, como se adquiere y ejerce la ideología dominante. No es por tanto extraña la conversión de la escuela elitista en escuela de masas por los estados democráticos capitalistas: es una necesidad. El modo de hablar, escribir, pensar, relacionarse, etc., que se ejercita y aprende en la escuela. configura el modo de hablar, escribir. pensar y relacionarse en el empleo. en la calle, etc. 'Por lo tanto, puede realmente decirse de la escuela que es una preparación para la vida. pero no en el sentido habitual que los educadores dan a esa consigna' (Jackson. 1968, 167), sino para una vida social alienada. 
Bowles y Gintis ponen el acento fundamental de la conexión entre la escuela y empleo en las 'relaciones sociales materiales que acontecen en la escuela'. 'La experiencia de la escolarización, y no meramente el contenido del aprendizaje formal, es central en este proceso' (Bowles - Gintis, 1976, 125), en el que la escuela está al servicio de la producción y sus requerimientos, haciendo que las necesidades personales se configuren de acuerdo con estos. Hasta tal punto que la propia identidad de los jóvenes y su autoconcepto se configura desde la experiencia de éxito/fracaso escolar en la escuela; no sólo en el logro académico, sino en las relaciones sociales con los iguales y con los adultos, como hemos podido comprobar en algunas investigaciones.

Por otra parte, si los objetivos y fines escolares fueran sola y prioritariamente los que formula como 'educativos' relacionados con el aprendizaje de 'contenidos' cognoscitivos, hace tiempo que la escuela habría sido sustituida por otros medios más eficaces, e incluso más baratos.

Son pues, las relaciones sociales de la escuela las que resultan. han resultado hasta ahora, funcionales al sistema tecno-económico; mucho más que los aprendizajes científicos, técnicos o profesionales.

Intentando hacer un breve resumen de los contenidos de estas relaciones sociales en la escuela y en el empleo, referidos por Fernández Enguita (1990), podríamos señalar los siguientes:

a) Importancia del orden, la autoridad y la disciplina en un contexto de relación no voluntaria.

b) Relaciones sociales impersonales y burocratizadas, donde la persona se reduce al rol y su juego.

c) La alienación del trabajo escolar para poderlo adaptar al trabajo-empleo capitalista o burocrático. El producto de la escuela es el título y no tanto el aprendizaje; un título que sólo vale en el mercado (si vale). El proceso de la escuela (qué, cuándo, para qué, etc., aprender) lo determinan otros. Tanto el método, el horario, etc.; vienen determinados y en función de conformar (formar con) a los individuos a los requisitos de un trabajo alienado en sus fines, procesos y medios en el sistema capitalista.

d) Selección de los rasgos caracteriales que son reforzados y castigados. Como señala nuestro autor, analizando diversos estudios:

'la actitud de sumisión a la autoridad se mostró tan buen predictor del rendimiento como el test verbal y mucho más que el C. I.' (Fernández Enguita, 1990, 210).

e) Motivación mediante recompensas extrínsecas. No se aprende a trabajar sino en función de un título o un salario. De donde resulta una necesidad compulsiva de buscarse a sí mismo y la satisfacción de las propias necesidades en otro ámbito: el consumo. Un consumo que consume al consumidor.

f) La competencia insolidaria. 'El éxito de otro es mi fracaso, y su fracaso mi éxito' (Fernández Enguita, 1990, 220). Pero descubriendo que:

'el mito de la igualdad de oportunidades corresponde a la realidad de la desigualdad obligatoria, siendo así que las posibilidades de quedarse en el fondo son mucho mayores que las de llegar arribat. El conocimiento nuevo sólo tiene un significado dentro de la perspectiva del anterior. Las escuelas defendieron alguna vez ese principio con tanto impetu que la palabra

\footnotetext{
5 J.M. Redondo. (1998). 'Características psicosocioeducativas de los alumnos que fracasan en el primer ciclo de la enseñanza media en el País Vasco. 'Revista Enfoques Educacionales. Vol. 1 No 2. 1998. Págs. 117-189.

6 Es significativa la nota del autor: Ona de las altemativas que se ofrecen a la solidaridad de la clase obrera es la idea de la aportanidad individual -de la escalera. Proporcionar dicha escalera se ha constituido en un servicio: en la indastria, en la educación y en todas partes.. Sin embargo. la escalera es un simbolo perfecto de la idea burguesa de la sociedad, porque si bien ofiece la oportunidad de ascender. es un dispositivo que sollo se puede usar individualmente: cada cual sabe por la escalera sólo. Mi opinion es que la versión escalonada es objetable en dos aspectos relacionados entre si: primero, debilita el principio del mejoramiento combin, que debe ser un valor absoluto; segundo, endula el veneno de la jerarqua, particularmente al ofrecer la jerarquía del mérino camo algo diferente. en su tipo. a la jerarquáa del dinero o de la cana'. Raymond Williams. Culture and Society, 1780-1950 (Hamondsworth. Middlesex: Penguin Books. Ltd.. 1958). PP. $317 / 18$.
} 
escolástico aún significa oprobio en ciertos círculos. Las modernas escuelas han dado un giro completo. Aparentemente toda es significado, pero de hecho se reservan su cortesía para los casos relevantes. Habiéndose convertido en el portal de todas las delicias seculares, no se debieran asombrar de que los estudiantes echen la puerta abajo.' (Reimer, 1970, 63).

Podríamos decir sin temor a equivocarnos, que si la integración económica keynesiana pudo convertirse en ideología social legitimadora fue gracias a la escuela y a su ideología de la igualdad de oportunidades. La democracia es compatible con el capitalismo en la medida en que los individuos justifican ideológicamente la desigualdad como consecuencia de las diferencias individuales descubiertas por la escuela e imputadas a la ley natural de la distribución desigual de las capacidades humanas. Si en un sistema democrático no puede justificarse las diferencias en razón de la riqueza externa, puesto que todos somos formalmente iguales; si parece poder justificarse que la libertad de cada uno con sus posibilidades naturales (capacidades) sea la explicación de las demás diferencias. No tiene nada de extraño en este contexto el proceso hacia la tecnocracia en los ámbitos económicos, políticos y culturales.

La primera alienación que realiza la escuela es la de aislar a los individuos de su clase social, a la persona de su comunidad (Mounier), con la justificación de realizar un proceso de socialización. Socialización sí, pero al servicio de los intereses del grupo social dominante y de su modelo de relaciones sociales. Esta socialización hace creer a los individuos que son propietarios de su saber, cuando en realidad es el capital el propietario del saber utilizando a los individuos como almacén-banco del mismo ${ }^{7}$. Esta utilización no se hace sin alterar el ser mismo de la persona, sin apropiarse al mismo tiempo de la conciencia: de sí, de los otros y del mundo.

g) División del trabajo. Especialmente división entre trabajo intelectual digno y trabajo manual indigno. Pero ambos meros trabajos de ejecución, con renuncia a la creatividad.

h) Sometimiento a una evaluación ajena que determina el valer de la persona, el valer y el valor desde los criterios de valor de uso y de cambio del mercado laboral y social capitalista. Evaluación que clasifica por el rendimiento escolar: otra forma de llamar en la escuela a la productividad (valor de uso por el capital de la fuerza de trabajo). En función de esta evaluación se reparten las recompensas, pero de forma desproporcionada, ya que se trata de potenciar la desigualdad de resultados que haga crecer en los individuos el afán de valer más ${ }^{8}$.

i) Selección y estratificación social basada en la propia autoconciencia estratificada. La escuela elige a los mejores (ya elegidos por su clase de partida), pero justifica con su elección el rechazo de los peores (ya rechazados por su clase de partida). Y en esto, como en todo, las excepciones confirman y justifican la regla.

Pero no concluye ahí, 'la escuela consigue que cada cual se sienta único responsable de su suerte' (Fernández Enguita, 1990, 241), matando en su origen toda posible conciencia de 'clase social oprimida'.

Es más, parece que los que tienen éxito no lo atribuyen a sus capacidades o dones naturales, sino a su esfuerzo personal (Masjuan y Codina, 1991, 105). Quizás sólo ellos saben el esfuerzo que les ha costado el someterse para tener éxito. Quizás es esa capacidad de sumisión confirmada por el titulo escolar la que demanda el mercado de trabajo.

Tener más títulos educativos no es una consecuencia de una mayor inteligencia, sino simplemente una recompensa por soportar más tiempo el poder que se padece en ella (la escuela)' (Feito, 1990, 292).

\footnotetext{
7 Una reflexión profunda desde esta perspectiva es el libro de Ignacio Fernández de Castro 'Sistema de Enseñanza y democracia' ya citado. De todas formas. la alineación en la persona producida por esta escuela de enseñanza 'bancaria' es profundamente analizada por P. Freire en todos sus libros. (1969) 'La educación como práctica de la libertad'. Tierra Nueva. Montevideo. (1971) 'Extensión o comunicación' Tierra Nueva Montevideo. Y'otros...

8 Es interesante estudiar esta realidad en relación a la estratificación de los salarios en función de los títulos escolares y las areas del conocimiento y profesionatización.
} 
De la lectura de lo señalado hasta aquí parecería derivarse un ajuste, si no entre educación y trabajo, sí entre sus bonsais escuela y empleo. Un breve momento de reflexión nos lleva a concluir que no es así. Entre escuela y empleo acontecen graves contradicciones. Unas derivadas de aspectos insuficientemente analizados en lo expuesto hasta aquí sobre los modos de producción que operan en la sociedad democrática capitalista y sus transformaciones actuales. Otras de las funciones contrapuestas que la escuela debe cumplir cara al subsistema socio-político democrático. Otras al rechazo que, desde otros valores, tiene la escuela por parte de determinados colectivos, pues estamos en una compleja sociedad multicultural y pluralista.

\section{2. La complejidad del subsistema tecno-económico y sus transformaciones actuales.}

La realidad de la economía es más compleja que la simple definición de capitalista. En la sociedad de los actuales Estados Democráticos capitalistas conviven y compiten cuatro modos de producción: el capitalista (MPC), el mercantil (MPM), el burocrático (MPB) y el doméstico (MPD). (Fernández Enguita, 1987, 21-36). Cuyas características recogemos en el siguiente Cuadro 1.

Cuadro $\mathrm{N}^{0}$ 1: Características de los modos de producción

\begin{tabular}{|l|c|c|c|c|}
\hline & MPC & MPM & MPD & MPB \\
\hline Produce valores de uso & sí & sí & si & sí \\
\hline Produce valores de cambio & sí & sí & no & no \\
\hline i. e. produce para el mercado & sí & sí & no & no \\
\hline Demanda solvente predomina sobre necesidades & si & si & no & no \\
\hline Manipula las necesidades & sí & no & no & no \\
\hline Supone organización compleja & si & no & sí & no \\
\hline El trabajador controla el proceso & no & sí & no & si \\
\hline Produce trabajo excedente & si & no & no & no \\
\hline Predominan bienes sobre servicios & sí & si & no & sí \\
\hline Elevada composición técnica & sí & no & si & sí \\
\hline Distribuye más de lo que produce & no & no & sí & sí \\
\hline Interferencia otras csferas no económicas & no & no & \\
\hline
\end{tabular}

Filente: Fernánde: Enguita (1987)

La escuela en cuanto reflejo y reproducción de las relaciones sociales de producción se caracteriza por lo ya señalado en el apartado anterior en cuanto al MPC, también en cuanto a la ideología individualista del MPM (pequeña burguesía, clases medias profesionales (Lerena, 1976)). Pero al mismo tiempo se rige por pretendidos criterios igualitarios y de participación democrática propios del sector público (MPB). Es decir, 'puede decirse que la escuela reúne la ilusión meritocrática del modo de producción mercantil, las relaciones sociales en el proceso de trabajo características del modo de producción capitalista y los criterios distributivos pertenecientes al modo de producción burocrático'.

Esta complejidad, en el momento actual se hace crítica por efecto de la crisis de crecimiento económico, la masificación de la cesantía, etc. Y la escuela resulta disfuncional por generar más expectativas democráticas que las que ofrece el MPC, más necesidad de empleos asalariados que los que ofrece el mercado y la administración (MPB), y sustituir progresivamente en su avance a la familia (MPD), desanimando por otra parte la libre iniciativa (MPM). 
Si en una época la escuela, siguiendo las teorías del capital humano, fue considerada una inversión productiva al pensarse que más educación incrementaba la productividad posterior en el trabajo; hoy, por efecto de la masificación de las escuelas y la reducción del empleo, sabemos que no es una relación lineal. Y que el mito de la escuela como vehículo de igualación social no es viable. Pero también que no parece 'razonable' gastar más recursos públicos en escuela, desde el punto de vista de la productividad económica.

Pero al mismo tiempo tenemos la necesidad de buscar explicación al crecimiento de la demanda de más escolaridad (Sanchís, 1991, 119-120). Los individuos siguen demandando escuelas para acceder a mejores empleos: el título es condición necesaria aunque no suficiente. Los Estados tienen que hacer algo con los jóvenes cesantes y no pueden cuestionar su propia legitimidad reduciendo las inversiones en escolarización, sino que más bien las incrementan para compensar la deslegitimación de la cesantía masiva. Este aumento tiene rentabilidades individuales para los mejores, pero muy poca rentabilidad social global. Es decir, 'el margen de maniobra de la política educativa contra el paro y la pobreza es muy limitado', (Sanchís, 1991, 17) a lo más puede alterar la incidencia de la cesantía sobre algún colectivo específico. En cambio para el individuo con capacidades, más escuela es una opción racional que le posibilita un empleo más cualificado y más estable.

Todo este cúmulo de contradicciones nos lleva a que la relación entre escuela y empleo no puede ser efecto de una adecuación de aquella a éste, sino también de cambios profundos en el sistema económico. Una participación de los trabajadores en las decisiones y en la propiedad que llamamos 'democracia económica', en la línea de apostar por la 'sustantividad democrática' (Freire, 1990, 6.).

Junto a todo lo descrito, la revolución tecnológica está generando un cambio en las cualificaciones laborales. Por una parte las nuevas tecnologías requieren mayor cualificación técnica en un porcentaje cada vez más reducido de empleos; pero al mismo tiempo, mayor porcentaje de empleos ofrece un trabajo cada vez más degradado (Sanchís, 1991, 138-145). Aunque sobre esto nos extendimos en otro lugar al analizar la cesantía masiva ${ }^{y}$, quisiéramos ahora señalar, por su importancia, que estos procesos no son en modo alguno aleatorios y que en su articulación social suponen un conflicto de clases y de grupos que se salda con un discurso ideológico que justifica opciones políticas, y no por determinaciones tecnológicas y/o económicas. Son posibles otras salidas a la actual crisis que las que se están ejecutando. Como señala Sanchís:

Lo que pone de manifiesto la investigación comparada es que la evolución de las cualificaciones no depende tanto de las características técnicas de los sistemas instalados cuanto de factores como la organización del trabajo, la política empresarial, la estructura de salarios o la disponibilidad de los trabajadores a aceptar determinados grados de hegemonía y' discrecionalidad por parte de la empresa. Por tanto, la necesidad de profesionalidad es un dato técnico sólo en parte, ya que también tiene algo que ver con la dinámica del conflicto industrial.

Más allá de los principios universales de organización del trabajo en la empresa, la perspectiva comparada ha puesto de relieve cómo es posible utilizar trabajadores con cualificaciones diferentes para llevar a cabo las mismas funciones, cómo es posible diseñar puestos de trabajo muy distintos para fabricar un mismo producto con una tecnología dada y cómo la empresa tiene varias alternativas, y no un sólo camino rígidamente predeterminado, a la hora de utilizar sus recursos humanos.

9 J. M. Redondo (1995) Op. cit Págs. $51-58$ 
El mito de los imperativos tecnológicos ha sido desenmascarado también por los documentados análisis de Noble, que ha sido profesor de historia de la tecnología en el Massachusetts Institute of Technology durante años. Estudioso de las relaciones entre Tecnologia y Sociedad, su tesis fundamental es que no hay determinismo tecnológico, sino, decisiones humanas libremente adoptadas que llevan la tecnología por uno u otro camino con sus correspondientes repercusiones sobre la calidad del trabajo, decisiones que han sido tomadas tanto en función de criterios técnicos como sociales' (Sanchis, 1991, 55).

De esta misma opinión son Lewin y Rumberger cuando señalan:

Las posibilidades que hay en relación con las nuevas tecnologías no solamente dependen de las características que tengan las tecnologias en símismas, sino también de como se incorporen de forma concreta a la organización del trabajo. La misma tecnología puede tener impactos mut. diferentes en el empleo yen las exigencias de cualificación de los trabajadores, de acuerdo a las distintas estructuras organizativas del trabajo' (Lewin-Rumberger; 1987, 123).

Ante esta realidad, nuevamente compleja, es evidente que la escuela tiene también su influencia en el futuro de la economía, ya que ésta depende de la preparación de los efectivos laborales provenientes del aquella. 'La educación no sólo responde a las necesidades del trabajo, sino también tiene el poder de transformarlas' (Lewin - Rumbenger, 1987, 128). De aquí que el aumento de la escolarización y el gasto público en educación no es sólo una opción de política social del Estado Benefactor sino una opción de política económica.

La resolución de las contradicciones internas de las escuelas e internas de la sociedad no es algo ya determinado por la inercia de los acontecimientos, sino, que va a depender de la capacidad de los jóvenes de entender y actuar en este marco complejo sin desvincular los aspectos más técnicos de los más políticos o de sus repercusiones económicas y culturales. Se demanda una educación, por la que la escuela debe optar. que posibilite un 'pensar global y un actuar local', sin refugiarse en el localismo estrecho, ni perderse en la impotencia de la globalidad inabarcable ${ }^{l i}$.

Algo de lo indicado más arriba puede estar ocurriendo cuando se habla de sobrecualificación de la fuerza de trabajo. Parece que el crecimiento económico ha propiciado un aumento de la enseñanza independiente de los requerimientos del sistema económico (Carabañas, 1987, 174185). En este contexto, el ajuste entre demanda y oferta no responde a un sólo criterio, por ejemplo más escolarización; sino que se articulan varios: segmentación del mercado " por niveles educativos (Cachón Rodríguez, 1991, 111-135); urgencia por encontrar trabajo; y evitación por parte de las empresas de la sobreeducación. Contra lo señalado al reflexionar sobre la funcionalidad de la escuela al empleo, los empresarios ven una mayor educación como una incapacidad de adaptación a las necesidades y condiciones actuales de los empleos precarios y descualificados.

Estas constataciones nos llevan a plantearnos las otras funcionalidades de la escuela que compiten con las del subsistema tecno-económico.

\section{ESCUELA Y LEGITIMACIÓN: LA FUNCIONALIDAD SOCIOPOLÍTICA.}

La escuela además de servir a las necesidades de la economía, está situada en la esfera de los servicios públicos que realiza el Estado. La escuela realiza una legitimación simbólica del orden socio-político mediante la pretensión de la igualdad de oportunidades; la libertad de elección de centro educativo; la formalización de la participación democrática en la gestión de las 
instituciones educativas; y el énfasis, en sus discursos legales y curriculares, en un desarrollo educativo integral de los alumnos, y no meramente capacitación técnico-profesional o enseñanza propedeútica para el ingreso en las universidades ${ }^{12}$.

De esta forma, las pretensiones de la escuela desde esta funcionalidad entran en conflicto con las señaladas anteriormente referidas al empleo. Como señalan Carnoy y Levin:

La relación entre la educación y el trabajo es dialéctica -compuesta de una perpetua tensión entre dos dinámicas, los imperativos del capitalismo y los de la democracia en todas sus formas-. Como producto y factor conformador, a la vez, de la discordia social, la escuela está necesariamente atrapada en los grandes conflictos inherentes a la economía capitalista y un Estado capitalista y' la base democrática del Estado capitalista liberal' (Fernández Enguita, 1987, 49).

\section{Bowles y Gintis llegan a conclusiones semejantes según recoge este texto:}

'La contradicción central de los sistemas educativos en las sociedades de capitalismo avanzado se deriva de dos aspectos de su localización en la totalidad social. Primero: forma generalmente un subsistema de la esfera del Estado y, por tanto, está directamente sujeta al principio de los derechos otorgados a la persona. Segundo: la educación desempeña un papel central en la reproducción de la estructura politica del proceso de producción capitalista, que a su vez está legitimado en los términos de los derechos otorgados a la propiedad. Así pues, la educación está directamente imvolucrada en la articulación contradictoria de las esferas en el capitalismo avanzado, lo que se expresa en términos de la dicotomía propiedad/persona: la educación reproduce los derechos de la propiedad, mientras que está en si misma organizada en los términos de los derechos de las personas' (Fernández Enguita, 1987, 50).

Pero la realidad es algo más compleja, ya que cada ámbito está sometido a sus propias contradicciones. Si las propias del ámbito tecno-económico ya las hemos señalado en el apartado anterior, ahora debemos centrarnos en las del ámbito sociopolítico.

El propio subsistema sociopolítico está sometido a fuertes contradicciones entre su pretendido discurso democrático liberal de igualdad y participación, y su realidad perversa ${ }^{13}$ de burocratización, autoritarismo y representación.

La escuela asume esta contradicción interna y al interiorizarla la trasforma en un conflicto interno propio: entre la participación de la comunidad (los padres y la comunidad local) y la autoridad de la administración pública (modelo burocrático). El proceso de descentralización administrativa y curricular trata de resolver este conflicto de forma constructiva.

Pero también existe conflicto entre la participación de los jóvenes en su propio proceso y la autoridad docente. Aquellos exigen el cumplimiento de los discursos participativos y democráticos que formulan las leyes, estos exigen la autonomía y las competencias de su cualificación profesional (a modo de profesionales liberales o catedráticos); y la relación entre ambos está sometida a los requerimientos contradictorios de la burocracia (incluso de la propia dirección de las escuelas y de los municipios) y de la economía.

La escuela, en cuanto burocratizada, tiende a determinar ella misma las necesidades que trata de satisfacer; y al mismo tiempo pretende responder a las necesidades de la economía y a las de las personas, a sus derechos. Al intentarlo, asume las mismas perversiones del sistema democrático en la sociedad capitalista y que podríamos resumir en: enseñar a delegar la responsabilidad, la iniciativa, la propia conciencia, etc. Existe pues una contradicción esencial en

12 Cf Objetivos Transversales de la Educación Básica y Media de la actual Reforma Educativa Chilena,

13 J. M. Redondo (1995) Págs, 43-50. 
la escuela que le impide realizar verdadera 'educación', 'los objetivos proclamados por los textos legales y por los programas de estudio son incompatibles con los reglamentos administrativos' (Coleman - Husen, 1985, 62-63).

Por otra parte tampoco puede, a un tiempo, conseguir instaurar la igualdad de los resultados y servir a la estratificación social y laboral. Por lo que su resultado sólo puede ser lo que es: éxito y fracaso. Exito para unos y fracaso para otros.

Es esta compleja realidad la que genera permanentemente la necesidad de fundamentar la legitimidad de la escuela, del gasto público en escolarización, y a través de él de la democracia; con reformas.

'Ocurrir y pasar para que nada pase y no ocurra nada. Para que no haya cambio son necesarios muchos cambios, y esto liltimo es cosa que da mucho trabajo: algo tiene continuamente que estar ocurriendo y pasando. Dentro del ámbito de la enseñanza, y en esta áltima década, más justo que decir que ha pasado sería decir que han pasado: han pasado ministros y leyes. Han pasado los años. Dentro de este ámbito y' si, como se quiere, es necesario emplear los verbos currir y pasar, valdría decirlo en forma de parodia hamletiana: reformas, reformas, reformas' Lerena, 1986, 436).

Todas las demandas coinciden: más escuela. Más escuela para reducir las desigualdades, según la óptica mítica de las clases populares. Más escuela para un ajuste mejor y más eficiente zntre escuela y empleo (el de alto nivel) según los intereses de la clase media (titulados) y alta demandantes de títulos). Más escuela para ser más modernos según el mito político actual ${ }^{14}$.

'Todas estas diversas demandas, sin embargo, son incompatibles entre sí, y por ello ?roducen reformas que jamás cumplen todos sus objetivos, que son siempre insuficientes y que 'e'an por tanto a más reformas. Es la reforma educativa permanente'. (García, 1991, 141).

Pretender a un tiempo servir a la acumulación y a la legitimación llevará a una pérdida rogresiva de confianza en la escuela.

El sistema educativo se ve compelido a efectuar dos tareas dificilmente compatibles entre i: la producción de las habilidades, y capacitaciones necesarias a la reproducción ampliada del istema; y la neutralización, destrucción y gasto improductivo de las capacitaciones sobrantes' García, 1991, 144).

La política de seguir invirtiendo en escolarización cuando es sabido que 'el gasto y la zalidad de la escuela no tienen efecto sobre la calidad de la enseñanza' (Carabañas, 1991, 69), حarece obedecer a una búsqueda compulsiva de legitimación por parte de los Estados en una zoyuntura que desacredita continuamente sus propias premisas igualitarias (Offe, 1977, 192). Como ha analizado Boudon (1978, 55-57), aún cuando es deseable una permanente disminución ¿ las desigualdades en la enseñanza, no es cierto que esto implique una disminución de otras tormas de desigualdad social.

Más escuela supone más títulos y más desigualdad, pero al mismo tiempo menos valor de os títulos. Es decir, menos confianza en la escuela y menos integración social. Ante esto la única :eceta que parece aplicarse es la misma que deriva de la lógica de acumulación, más de lo mismo: nás escuela y más reformas.

La reforma de la Ley de 1970 en España pretendió distraer la necesaria reforma del sistema

- Vo es ajeno a esto el progresivo auge de la oferta y demanda de cursos de especialización. master. etc. 
politico dictatorial mediante una 'revolución silente: la igualdad de oportunidades' (Ortega, 1992. 43). Con esta revolución se propiciaba el camino individualista a la movilidad social a costa de la estrategia solidaria.

El éxito de la reforma podría resumirse en:

- Psicologización del medio escolar y énfasis en las diferencias individuales.

- Fortalecimiento de los valores y acciones individualistas.

- Reducción de la conflictividad social e integración marginal asumida de los 'fracasados escolares', desde la relevancia del mérito personal.

La reforma de la LOGSE (1989). la última reforma en España, además de una adaptación necesaria de la Ley del 70 a los requisitos de una situación democrática -!qué no es poco!-; abunda en el camino de la meritocracia y de la llamada igualdad de oportunidades, ahora llamada compensación de las desigualdades.

Parece intentar convencernos de nuevo, de la posibilidad de la igualdad de oportunidades desde un buen sistema educativo-escolar; pero la puesta en práctica impide creer en la realización de sus objetivos. Parece más bien pretender, por las prisas con que se realiza, 'que todo cambie para que todo siga igual' ('Gatopardo'). De nuevo la práctica nos desvela lo oculto, más allá de las loables intenciones que se formulan en los textos legales, el DCB (Diseño Curricular Base) y los Decretos de desarrollo de la Ley. Aunque de todas formas, según se desciende en el rango de los documentos ya se confirma la afirmación inicial.

Podríamos detenernos en un análisis de la Ley, pero solamente vamos a destacar un aspecto: la psicologización de la problemática social. Ocurre como si las justificaciones para la toma de deciciones no fueran valiosas si no se sustentan en la ciencia humana llamada psicología; cuando ésta es todavía hoy, una diversidad de escuelas, técnicas. etc.; fundamentadas en opciones antropológicas y filosóficas previas que determinan todo su cuerpo doctrinal; la mayoría de las veces cayendo en un psicologismo (Husserl, 1900). De forma que recurrir a ella, supone optar por determinada corriente de pensamiento cuyos fundamentos no se explicitan. Así:

sive en muchas ocasiones para disfrazar; bajo capa de pensamiento científico, lo que no son otra cosa que intereses políticos, decisiones que pueden beneficiar a un gran número de ciudadanos y ciudadanas, a colectivos sociales con intereses más o menos legítimos, etc.; pero al mismo tiempo atentan o no hacen suficiente hincapié en la defensa de grupos sociales más desfavorecidos y marginados' (Torres Santomé, 1991, 490).

La nueva terminología utilizada en la reforma puede ayudar a despistar la dimensión social de los problemas, seguir tecnocratizándolos y dejándolos en manos de cada vez más expertos profesionales. ¿Cómo si no explicar la poca importancia que se le está concediendo en la práctica al diseño en cada centro de su proyecto educativo, con la participación de todos los agentes sociales implicados? El recurso a la psicologización de los problemas es una tendencia de todas las tecnocracias que ciertamente garantiza un consenso social legitimador, pero que al olvidar las dimensiones sociales de los problemas que afectan a los grupos sociales más desfavorecidos y excluidos impiden su develamiento y defensa. No menos llamativo es el olvido de la pedagogía y sobre todo de los profesores.

Concretamente se olvida:

'explicitar claramente qué grupos de ciudadanos y ciudadanas se vienen encontrando en franca desventaja dentro de los centros educativos y de las aulas; por qué y cómo se puede aminorar semejantes injusticias para con tales colectivos sociales. (...) cómo se genera el fracaso educativo, a qué colectivos sociales afecta y hasta que punto es verdadero fracaso o un fracaso artificial que sirve pare legitimar formas y grupos culturales y económicos; cómo se tergiversa 
la realidad, cono se propagan el sexismo, el racismo y en general las falsas expectativas y los mejuicios que acostuminum a funcionu contra los gripos sociales más desfavorecidos (Torres Santomé, 1991, 4961.

Sin estas explicitaciones es posible que el énfasis que se pone en la comprensividad no llegue a lograr éxitos. El éxito de la comprensividad dependerá. como indica Torres Santomé, no sólo de la acomodación de las propuestas de trabajo a los intereses y capacidades de los alumnos/ a. de respeto a su psicología: y de la capacidad de los profesionales de las escuelas para trabajar con metodología y recursos adecuados; sino de la cultura que se valore y que se genere en los ¿ntros escolares. Las culturas de clases. de géneros, de razas, de nacionalidades generan una suciedad y una escuela necesariamente multiculural. Para nosotros es especialmente relevante lo yue hace referencia a la cultura llamada 'popular-obrera' de los barrios periféricos y a las llamadas culturas juveniles'.

'Y es obvio. que un discurso preponderantemente de corte psicológico, más centrado en tindividuo 'universal', descontevtualisado en sus dimensiones sociales e históricas, sin hablar may claro de realidades y problemas como son éstos a los que venimos haciendo referencia no e' puede decir que vay a con buen pie a la conquista de tales méritos 'la igualdad de oportunidades "la compensación de desigualdades'. Tomres Santomé. 1991, 500).

Y al llegar a este punto. pasamos a analizar las funcionalidades de la escuela para el subsistema cultural-ideológico.

\section{LAS CULTURAS Y LA ESCUELA.}

El concepto 'cultura' es demasiado amplio. Casi todo en la realidad humana está teñido. o es simplemente cultura. Hay poco de 'natural' en lo que llamamos 'naturaleza humana'. Suizás sea el ser capaz de 'cultura' lo que constituye la verdadera 'naturaleza humana', con las consecuencias que de ello se derivan. Pero no vamos a detenernos en esto.

La política es cultura política: la economía es cultura económica. ¿Qué queremos expresar con esto? Sencillamente que detrás de las formulaciones políticas, económicas, científicas o educativas, existe una cultura que define los medios (formas) y los fines (contenidos) en función de unos 'valores'. Son los valores articulados en fines y medios los que definen una cultura.

Reflexionar sobre la función de la escuela como trasmisora-educadora de valores es abordar su funcionalidad cultural-ideológica. Siempre y cuando no reduzcamos los valores a meras ideas, sino que aceptemos que un valor se articula necesariamente en planteamiento (idea-cognición), uctitud (afecto-inclinación) y opción (decisión-volición), y se manifiesta en conductas. A veces incluso estas dimensiones no son congruentes.

Como ya hemos señalado anteriormente. lenguaje y pensamiento se articulan y se generan desde los actos sociales cargados de cultura. Hasta tal punto que podríamos decir que 'adquirimos' nuestros valores (no los 'elegimos') en las relaciones sociales significativas. Podemos decir que tenemos un valor cuando lo hemos experimentado y es activo en nuestra conducta.

Hall. estudiando la evolución humana desde los trabajos de Maslow, Erikson y Kohlberg concluye que 'el desarrollo de los valores concide con el de la conciencia' (ICE, 1993, 15). Para poder analizar los valores de las personas o instituciones Hall y Tonna proponen, no sólo inducir estos de las cualidades de sus conductas, sino acudir a las palabras. Acudir a las palabras-valor que en todas las culturas expresan las cualidades valiosas de las conductas, al estar cargadas de ignificado. Estas palabras-ialor articulan la conexión entre la realidad interna y externa de las 
personas; su experiencia almacenada en 'imágenes interiores' que se hace conscientes al articularse en lenguaje; un lenguaje cargado de un significado propio y que busca un sentido (dirección) a la acción. Además las palabras-valor forman conjuntos dinámicos interactivos. (ICE, 1993, 18-19).

Si todo esto es así; es claro que cada individuo tiene sus propias experiencias y sus propios valores. Y que las primeras experiencias vitales en la familia, el barrio, etc., configuran un lenguaje y unos valores iniciales cargados de 'cultura'.

Por otra parte la escuela tiene su propia cultura articulada en lenguaje, valores, conductas premiadas, metas, etc.; y que, cómo ya indicamos anteriormente, corresponden a la clase media. Por ello, todos aquellos niños y jóvenes que viven otra cultura, valores, lenguaje; están 'condenados' a experimentar un conflicto que pueden resolver como rechazo de la escuela o como asimilaciónacomodación a la escuela, bien de forma real o sólo aparente. Y esto no determinado por las llamadas 'capacidades cognitivas' que pretende desarrollar la escuela.

$\mathrm{Si}$ a título de ejemplificación pretendiéramos conocer los valores que subyacen en la LOGSE, descubriríamos lo ya referido en el apartado anterior (ICE, 1993, 177-178):

- Predominio de lo institucional y burocrático, y de la eficacia a corto plazo.

- Valor del trabajo, la dignidad humana y la justicia social.

Aún cuando se descubre una fuerte coherencia interna en toda la ley se echan en falta valores referentes a las destrezas interpersonales, y sobre todo a las imaginativas; una mayor valoración de lo gratuito no instrumental; y sobre todo la poca atención a la autoestima como motor de desarrollo humano y de la capacidad de innovación. Hay por otra parte un exceso de valoración, hasta situarlo como central, del trabajo. Lo cual es claramente contradictorio con el futuro social perfilado en las previsiones más generalizadas y el análisis sobre cesantía juvenil.

El volcar las mejores energias y los mavores esfuerzos en la buisqueda de este tipo de funcionalidad podría provocar una pérdida de visión sobre lo que puede y debe ser la educación además de estructuración de procesos para la consecución de títulos' (ICE, 1993, 169).

Pretender desarrollar valores como la dignidad de la persona humana y la justicia social o la igualdad mundial basándolos en el desarrollo de la autocompetencia lograda para y en el trabajoempleo es hacer depender estos valores del mercado y declinar las posibilidades de la escuela como 'ámbito' generador de valores para el cambio social.

No es extraño, desde estas opciones, que se hable cada vez más a nivel mundial de 'analfabetismo funcional'. No tanto porque haya disminuido el nivel de instrucción, que no lo ha hecho (Welch - Freebody, 1990, 259). O porque las exigencias formuladas para insertarse en la sociedad, cada vez más compleja, hayan aumentado; que si lo han hecho (Welch - Freebody, 1990.266), aunque no tanto por los requerimientos implícitos de los puestos de trabajo (Fernández Enguita, 1990), sino por el efecto 'mal del diploma' que Dore refiere así:

En todos los paises, tanto en Gran Bretaña como en la India, en Rusia como en Venezuela, la escolarización es más frecuentemente cualificación-adquisición de educación de lo que lo fue én 1920 o incluso en 1950. Y más que cualificación-aprendi-aje es SOLO cualificación y aprendizaje ritual tediosa. Llena de ansiedad y fastidio, destructora de la curiosidad y la imaginacion: en resumen anti-educativa' (Welch - Freebods. 1990. 267).

Es decir. la función de criba y selección domina sobre la tradicional de 'educación' (de ahí nuestro reparo constante de llamar al sistema escolar sistema educativo). La crisis de alfabetización es pues una creación social, no tanto en función de los requerimientos de la economía directamente. cuanto en relación a la función legitimadora de la escuela. 
Lo que realmente puede decirse que se ha perdido de los intentos del pasado en cuanto a la alfabetización es el iáal denocrático tradicional: la alfabetización, a este respecto, es menos impontante como clave para linas habilidades técnicas que como el 'sine qua non' de un Estado democratico moderno. Por ello Appel (Lankshear - Lawler, 1987) añade. 'cuando los grupos dominantes declaran que hay una crisis, debemos preguntamos 'iqué crisis es ésta?' y' 'qué beneficios se obtienen de las soluciones propuestas?'. Las recientes declaraciones de una crisis de alfabetización en cierto número de naciones no son inmunes a estas preguntas. Es posible alegar que debido al cambio de la atención pública hacía los problemas de la educación, las tuentes reales de la crisis actual se dejen sin analizar. Esto es, la crisis de la economía politica del capitalismo se traspasa de la economía al Estado. El Estado, entonces, traslada a su vez la rrisis hacia la escuela. Ast. cuando existe un grave desempleo. la desaparición de pautas tradicionales de autoridad, etc; la culpa recae en la falta de habilidad de los alumnos, en sus actitudes, en su analfabetismo funcional. La cultura implica poder la posesión del capital cultural sobre el que se basa el poder (Bourdien 1970 ) se hace accesible de forma distinta a los diversos grapos de la sociedad. Los ataques a los niveles generales de alfabetización en la sociadad intentan ocultar este proceso. Por otra parte. su fanción es precisanente la de establecer esta cuncuión entre algunas formas privilegiadas de alfabetización y la perpetuación del poder sconónico y cultural de la sociedad' (Welch - Frebody, 1990, 275).

Así situado el problema podemos adentrarnos adecuadamente en el análisis de los mecanismos internos de la escuela que operan la desigualdad y el fracaso de los colectivos desfavorecidos y marginados. y' que ya hemos desarrollado en otro lugar ${ }^{15}$.

\section{BIBLIOGRAFÍA}

Althusser, L (1970)

Baudelot, Ch. y Establet, R. (1976)

Boudon, R. (1978)

Bourdieu, P. y Passeron, J. C. (1970) La reproducción. Barcelona. Laia.

Bowles, S. y Gintis, H. (1976)

Bruner, J. (1981)

Cachón Rodríguez, L. (1991)

Carabaña, J. (1991)
Ideología y aparatos ideológicos del Estado. Barcelona. Anagrana,

La escuela capitalista en Francia. Madrid. Siglo XXI.

'Educación e Igualdad'. En VV. AA.: Políica, igualdad social y educación. Madrid. MEC.

La instrucción escolar en la América Capitalista. Madrid. Siglo XXI.

'Vygotsky: una perspectiva histórica y conceptual'. Infancia y Aprendizaje; (14), 8 .

'Segmentación del mercado de trabajo y niveles educativos'. En VV. AA: Sociedad. Cultura y Educación. Madrid. CIDE-MEC.

'El gasto público en Enseñanza y sus justificaciones'. En VV. AA. Sociedad. Cultura y Educación. Madrid CIDE-MEC.

15 J. M. Redondo (1997) y J. M. Redondo (1998) ya citados. 
Chamboredon, J. V. (1983)

Charlot y Figeat $O$.

Coleman, J. S. y Husen, T. (1985)

Combs, P. H. (1968)

Doise, W. (1978)

Faure, E. (1972)

Feito, R. (1990)

Fernández Enguita, M. (1985)

Fernández Enguita, M. (1987a)

Fernández Enguita, M. (1987b)

Fernández Enguita, M. (1988)

Fernández Enguita, M. (1990a)

Fernández Enguita, M. (1990b)

Foucault, M. (1976)

Freire, P. (1990)

García, E. (1991)

Gobierno Vasco (1988).

Goodman, P. (1970)

ICE Universidad de Deusto (1993)

Illich, I. (1970)
'Problemas de la transmisión y problemas del control social en sociología de la Educación'. En VV. AA.: Perspectivas actuales de la sociología de la Educación. Madrid. ICE de la U. Autónoma de Madrid.

Citado por Fernández Enguita, M. (1990').

Informe OCDE Inserción de los jóvenes en una sociedad en cambio. (versión castellana en 1989. Madrid. Narcea.).

La crisis mundial de la educación. Barcelona. Península.

'Images, Representations Ideologiques et Experimentation PsychoSociologique'. Information sur les Sciences sociales. Citado por Perret-Clermont, A. N. (1979) Procesos psicosociológicos y fracaso escolar'. Infancia y Aprendizaje; (6), 5.

Aprender a Ser. Madrid . Alianza Universal.

Nacidos para perder. Madrid. CIDE-MEC.

Trabajo, Escuela e Ideología. Madrid. Akal.

La escuela en el capitalismo democrático. México. Universidad A. de Sinaloa.

'Educación y modos de producción'. En VV. AA. El fracaso de la Escuela. San Sebastián. Erein.

'El rechazo escolar: ¿altemativa o trampa social?'. Política y Sociedad; (1).

La cara oculta de la escuela. Madrid. Siglo XXI.

Educación, Formación y Empleo en el umbral de los noventa. Madrid . Proyecto GETAFE 90. Madrid. CIDE-MEC.

Vigilar y Castigar. México. Siglo XXI.

Citado en entrevista por Jover. A. (1990) La formación ocupacional. Madrid. Editorial Popular-MEC.

'Reforma escolar. acumulación. legitimación y estado de bienestar'. En VV. AA.Sociedad. Cultura y Educación. Madrid. CIDE-MEC.

'Jóvenes hacia el Futuro'. Servicio de Educación Compensatoria e Iniciación Profesional.

La des-educación obligatoria. Barcelona. Fontanella.

Los valores en la LOGSE. Bilban. ICE Universidad de Deusto.

La sociedad desescolarizada. Barcelona. Barral. 
Jackson, P. W. (1968)

Lerena, C. (1976)

Lerena, C. (1983)

Lewin, H. y Rumberger, R. W. (1987) 'Requisitos educativos para el futuro mercado de trabajo'. En

Masjuan, J. M. y Codina, J. (1991)

Offe, C. (1977)

Ortega, F. (1992)

Page, A. (1977)

Perret-Clermont, AN. (1979)

Reimer, E. (1970)

Sanchis, E. (1991)

Torres Santomé, J. (1991)

Welch, A.R. y Freebody, P. (1990)

Wertsch, J. V. (1988) Congreso Mundial Vasco. Gobierno Vasco. Planificación de la Educación y mercado de Trabajo. Madrid. Narcea.

La vida en las aulas. (Edición Castellana 1975. Madrid. Morata).

Escuela. Ideología y Clases sociales. Barcelona. Ariel.

Reprimir y Liberar. Madrid. Akal.

La atribución causal del éxito o el fracaso en los procesos de inserción en la vida adulta'. En: Sociedad. Culıura y Educación. Madrid. CIDE-MEC.

Lo stato nel capitalismo Maturo. Milán. Estas Libri.

'Las ideologías de la Reforma Educativa de 1970'. Revista de Educación. Extra Ley 1970)

La conomía de la Educación. Buenos Aires. Kapeluz.

'Procesos psicosociológicos y fracaso escolar'. Infancia y Aprendizaje: (6). 5

La escuela ha muerto. Barcelona. Barral.

De la escuela al paro. Madrid. Siglo XXI.

'La reforma educativa y la psicologización de los problemas sociales'. En VV.AA.: Sociedad. Cultura y Educación. Madrid. CIDE-MEC.

'CCrisis de alfabetización o crisis de estado? Explicaciones de la actual crisis de alfabetización'. Revista de Educación; (293), 259. Madrid. CIDE.

Vygotsky y la formación social de la mente. Barcelona. Paidós. 